\title{
A broad clinical high risk mental state (CHARMS): \\ Methodology of a cohort study validating criteria for pluripotent risk
}

\author{
Jessica A. Hartmann ${ }^{1,2,}{ }^{,}$, Barnaby Nelson ${ }^{1,2}$, Rachael Spooner ${ }^{1,2}$, G. Paul Amminger ${ }^{1,2}$, Andrew \\ Chanen $^{1,2}$, Christopher G. Davey ${ }^{1,2}$ Meredith McHugh ${ }^{1,2}$, Aswin Ratheesh ${ }^{1,2}$, Devi Treen ${ }^{3}$, Hok Pan \\ Yuen $^{1,2}$, Patrick D. McGorry ${ }^{1,2}$
}

\footnotetext{
${ }^{1}$ Orygen, the National Centre of Excellence in Youth Mental Health, Melbourne, Australia

${ }^{2}$ Centre for Youth Mental Health, University of Melbourne, Melbourne, Australia

${ }^{3}$ Institute of Neuropsychiatry and Addictions (INAD) - Parc de Salut Mar Barcelona, Barcelona, Spain
}

Running head: Towards a pluripotent at-risk mental state

${ }^{*}$ Corresponding author. Contact details: Orygen, The National Centre of Excellence in Youth Mental Health, 35 Poplar Rd (Locked Bag 10), Parkville, Victoria 3052, Australia.

Jessica.hartmann@orygen.org.au, +61 393422800.

Acknowledgement

This work is supported by a grant from the John T Reid Charitable Trust and the Colonial Foundation. JAH is supported by a Netherlands Organization for Scientific Research (NWO)-Rubicon Grant (825.15.015). PDM was supported by a Senior Principal Research Fellowship from the NHMRC (ID: 1060996); GPA was supported by NHMRC Senior Research Fellowships (ID: 1080963); CGD was

This is the author manuscript accepted for publication and has undergone full peer review but has not been through the copyediting, typesetting, pagination and proofreading process, which may lead to differences between this version and the Version of Record. Please cite this article as doi: 10.1111/eip.12483

This article is protected by copyright. All rights reserved. 
Towards a pluripotent at-risk mental state

supported by an NHMRC Career Development Fellowship (ID: 1061757), BN was supported by a University of Melbourne Faculty of MDHS Research Fellowship.

PDM reported receiving grant funding from National Alliance for Research on Schizophrenia and Depression and unrestricted research funding from AstraZeneca, Eli Lilly, Janssen-Cilag, Pfizer, and Novartis, as well as honoraria for educational activities with AstraZeneca, Eli Lilly, Janssen-Cilag, Pfizer, Bristol-Myers Squibb, Roche, and the Lundbeck Institute.

This article is protected by copyright. All rights reserved. 


\begin{abstract}
Aim

The development of the ultra-high risk (UHR) criteria for psychosis created a new paradigm for prevention research in psychiatry. Since a) prevention research faces the challenge of achieving adequate statistical power when focusing on single low-incidence syndromes and b) early clinical phenotypes are overlapping and nonspecific, this study broadens the UHR state beyond psychosis as an outcome. The CHARMS (Clinical High at Risk Mental State) study aims to prospectively validate a set of transdiagnostic criteria to identify help-seeking young people at risk of developing a range of serious mental illnesses.

Methods

This paper describes the methodology of the CHARMS study, which involves applying the CHARMS criteria to a cohort of help-seeking young people aged 12-25 attending youth mental health services in Melbourne. New referrals meeting the CHARMS criteria are allocated to the CHARMS+ group; referrals not meeting CHARMS threshold are allocated to CHARMS- group (control group); referrals meeting criteria for a full-threshold disorder are excluded. Transition status and clinical and functional outcomes are re-assessed at 6 and 12 months.

Conclusions

This study will be the first to introduce and validate clinical criteria to identify a broader 'at-risk' patient population, which may facilitate young people's access to clinical services and early treatment by reducing the reliance on 'caseness' defined according to current diagnostic categories being required for service entry. These new criteria may introduce a new, transdiagnostic approach for understanding risk factors and pathogenic mechanisms that drive the onset of severe mental illness and the next generation of preventive intervention trials.
\end{abstract}

Key words: at-risk mental state; clinical criteria; subthreshold states; pluripotential; transdiagnostic

This article is protected by copyright. All rights reserved. 
Towards a pluripotent at-risk mental state

\section{Introduction}

The development of the 'ultra-high risk' (UHR) for psychosis criteria more than 20 years ago created a new paradigm for prediction research and subthreshold intervention in psychiatry ${ }^{1}$. However, research in the area has shown a reducing transition rate to psychosis ${ }^{2-4}$ and also a substantial rate of onset and persistence of non-psychotic disorders in the UHR population ${ }^{5-7}$ This presents a conceptual challenge but also the research problem of not having sufficient statistical power to identify predictors of psychotic disorder as an outcome and test preventive intervention strategies (by showing, for example, a reduced incidence rate of new cases) ${ }^{8}$. . Indeed, many recent UHR intervention studies have suffered from lack of power due to a reasonably low rate of transition to psychosis, their primary outcome ${ }^{10}, 11$. For example, both the EDIE-2 (early detection and intervention evaluation for people at risk of psychosis) trial and Neurapro trial showed modest $8 \%$ $11 \%$ transition rates over 12 months, which compromised the studies' ability to effectively test their respective interventions ${ }^{10,11}$. This issue has contributed to the proposal that prediction and prevention research should focus on high-risk groups with higher incidence rates and multiple risk factors $^{8,9}$. As proposed by Cuijpers (2003), one way to achieve higher incidence rates is to target a broad range of disorders as outcomes of interest, and not be limited to a single relatively low incidence disorder such as schizophrenia.

Conceptually, this requires a broadening of the 'ultra-high risk' state and its operationalisation into a transdiagnostic at-risk mental state, which is also in line with evidence regarding the non-specific nature of emerging psychopathology. For example, the majority of UHR clients fulfil diagnostic criteria for one or more mood, anxiety, substance use and personality disorders, and the criteria capture markedly elevated risk for exit syndromes other than psychosis ${ }^{5-7}$. It has been argued that this may reflect an 'early shared pathway' or a form of pluripotency of the early clinical phenotypes of mental disorders ${ }^{12}{ }^{13}$. That is, observed early signs and symptoms of mental ill-health may not indicate a fixed trajectory to particular diagnoses and may evolve into a range of different psychiatric syndromes $^{12,13}$.

The concept of pluripotency of early clinical phenotypes also aligns with the clinical staging model of psychiatry ${ }^{14-16}$, which parallels staging models in general medicine (e.g., cancer). This model positions an individual along a continuum of illness which is defined according to stages: Stage $0=$ no current 
Towards a pluripotent at-risk mental state

symptoms, Stage $1 a=$ help-seeking with distress, Stage $1 b=$ attenuated (i.e., sub-threshold) syndrome, Stages 2-4 = full threshold disorder with varying degrees of recurrence and severity. The staging model is also referred to as a 'trunk and branch' model, with the trunk representing the pluripotent risk of symptoms crystallising over time into particular syndromal branches, such as psychotic or affective disorders (see Figure 1) ${ }^{14-16}$. This model allows for so-called comorbid outcomes, e.g. emergence of both psychotic and affective syndromes in a particular individual. This conceptual framework can guide the search for risk and protective factors for disease progression.

\section{Clinical High at Risk Mental State (CHARMS) criteria}

The study investigators developed a set of criteria to operationally define the early clinical phenotypes of a range of exit syndromes. The term "Clinical High At-Risk Mental State" (an adaption of the original "at-risk mental state" term ${ }^{17}$ ) is used to refer to this composite definition. These criteria, developed on the basis of available evidence and expert clinical experience, are operationalised using a combination of validated instruments (see Table 1). The CHARMS approach aims to identify the sub-syndromal population at risk of severe psychopathology, providing an operational definition of a broad-spectrum ultra-high risk or pluripotent state. In terms of clinical staging, CHARMS corresponds to Stage $1 \mathrm{~b}$ ('attenuated syndrome').

We used subthreshold versions of specific disorders (i.e. psychosis, depression, mania, borderline personality disorder) as a basis for the CHARMS criteria because they provide useful late stage or 'end state' clinical phenotypes for which there are established treatment guidelines, but all of which have earlier stages with a need for care. Furthermore, global burden of disease data in young people aged 10-24 indicate prevention should focus on schizophrenia, unipolar depression and bipolar disorder, given that these disorders contribute the largest burden of disease in this age group ${ }^{18}$. Given that Borderline Personality Disorder is a common and significantly impairing disorder amongst this age group and is associated with help-seeking behaviour, it was also included as a target syndrome in the criteria ${ }^{19}$.

However, the proposed criteria (and chosen exit syndromes) are preliminary and the associated thresholds may not yet be valid or precise, and therefore require thorough empirical investigation. Therefore, we designed an observational study with the following aims:

This article is protected by copyright. All rights reserved. 
Towards a pluripotent at-risk mental state

(1) To prospectively establish the predictive and discriminant validity of the CHARMS criteria in a cohort of help-seeking young people meeting CHARMS criteria and a comparison control group.

(2) To identify clinical predictors of progression to full threshold syndromes, including anxiety, stress, sleep disturbance, general psychopathology, functioning, substance abuse, maladaptive personality traits and cognitive biases.

This paper presents the study design and methodology of the CHARMS study.

\section{Methods}

The CHARMS study adheres to ethical principles as formulated in the Declaration of Helsinki and is performed according to ICH-Good Clinical Practice (GCP). The study was approved by the local ethics committee (Melbourne Health Human Research Ethics Committee, \#HREC/15/MH/276) and participants provide written informed consent prior to study enrolment. For participants under 18 years of age, parental consent is also obtained.

Design

The CHARMS study is a longitudinal study, involving 160 participants who meet CHARMS criteria ('CHARMS+') and 160 controls ('CHARMS-'). The control group comprise young people with symptoms not reaching CHARMS criteria threshold. Assessment points are at baseline, 6 and 12 months.

Sample and setting

Potential participants are help-seeking young people aged 12-25 who are referred to Orygen Youth Health (OYH) or one of four headspace clinical centres in Melbourne, Australia. OYH is a multicomponent State Government funded mental health program for young people in western metropolitan Melbourne. The four headspace centres, located in the suburbs of Sunshine, Glenroy, Werribee and Craigieburn, provide universal access under a Federally-funded model of enhanced primary care to a broad array of mental health and welfare services. Inclusion criteria are: (i) Ability to give informed consent, (ii) help-seeking, and (iii) between the ages 12-25 years. Exclusion criteria

This article is protected by copyright. All rights reserved. 
Towards a pluripotent at-risk mental state

are: (i) documented history of intellectual disability, and (ii) current of past full threshold (Stage 2) disorder (psychosis, bipolar disorder, severe major depressive disorder, borderline personality disorder).

\section{Procedure}

Recruitment commenced in April 2016 and is expected to be completed in April 2018. In consultation with the relevant clinical teams, young people referred to $\mathrm{OYH}$ or headspace are approached by a research assistant (RA) in person or via telephone to discuss the aims of the study and their interest in participating. When a young person is interested and informed consent is obtained, a baseline interview is scheduled. During this baseline interview, the CHARMS criteria are formally assessed. If a participant exceeds the threshold for the CHARMS criteria (i.e. presents with a full threshold disorder), the participant is excluded from the study and the assessment is discontinued. If the participant meets the CHARMS criteria ('CHARMS+') or falls below the CHARMS threshold ('CHARMS-'), he/she is included in the study. After the structured interview conducted by the RA, the self-report measures are completed by the participant using an iPad. The duration of the baseline interview is approximately 2-3 hours.

Study participants are re-assessed at 6 and 12 months using the same interview measures and test battery with a few exceptions (see Table 2). For participants unable to attend a face-to-face followup interview, a telephone interview is administered. If participants are unable to be re-interviewed, their diagnostic status at last clinical contact is sourced from medical record files and state medical records.

RA's are trained by experienced researchers and clinicians on the Chief Investigator team. Inter-rater reliability will be established during the course of the study.

\section{Measures}

Table 1 presents a detailed description of the ascertainment of CHARMS criteria using the following four interview measures (CAARMS, SCID-5, QIDS-C, SOFAS).

This article is protected by copyright. All rights reserved. 
Towards a pluripotent at-risk mental state

\section{$\underline{\text { Interview measures }}$}

Comprehensive Assessment of At-Risk Mental States ${ }^{20}$ (CAARMS). The CAARMS is a semi-structured interview which was developed to identify help-seeking young people who are at UHR for psychosis $^{20}$. The full version of the CAARMS includes seven domains: positive symptoms, cognitive change/attention, emotional disturbance, negative symptoms, behavioural change, motor/physical changes, and general psychopathology ${ }^{20}$. Each domain in the CAARMS receives a global rating score $(0-6)$, a frequency score (0-6) and pattern of symptoms with substance use score (0-2). The positive scale also includes an additional distress score (0-100).

Structured Clinical Interview for DSM- $5^{21}$ (SCID-5) and the Structured Clinical Interview for DSM-5 Personality Disorders ${ }^{22}$ (SCID-5-PD). SCID-5 and SCID-5-PD are semi-structured interviews for systematically establishing clinical diagnoses based on the Diagnostic and Statistical Manual of Mental Disorders, Fifth Edition ${ }^{23}$. The SCID-5 is considered the "gold standard" in generating clinical diagnoses. Of the SCID-5-PD, only the borderline personality disorder module (BPD) and schizotypal personality disorder module (SPD) are assessed, which correspond to the modules used in SCID-IV ${ }^{24}$.

Quick Inventory of Depressive Symptomatology - Clinician rated ${ }^{25}$ (QIDS-C). QIDS-C is a clinicianrated 16-item questionnaire which assesses the severity of depressive symptoms during the previous week. All QIDS items are weighted on a 4-point Likert scale (0-3) with a higher score reflecting increasing symptom severity.

Social and Occupational Functioning Scale ${ }^{26}$ (SOFAS). SOFAS is an observer-rated scale that assesses social and occupational functioning on a 0-100 scale.

Global Functioning Scale: Social ${ }^{27}$ (GFS) and Global Functioning Scale: Role ${ }^{28}$ (GFR). GFS and GFR are complementary scales derived from the traditional GAF format. The GFS assesses quantity and quality of peer relationships, level of peer conflict, age appropriate intimate relationships, and involvement with family members. The GFR assesses age appropriate performance in school, work,

This article is protected by copyright. All rights reserved. 
Towards a pluripotent at-risk mental state

or home duties. Both scales are rated using a 1 (extremely dysfunction) to 10 (superior functioning) scale.

Young Mania Rating Scale 29 (YMRS). YMRS contains 11 clinician-rated items that assess severity of manic symptomology over the previous 48 hours. Each of the 11 items are anchored by five specific symptom severity descriptions. The YMRS is considered the 'gold standard' of mania rating scales ${ }^{30}$.

\section{$\underline{\text { Self-report measures }}$}

Depression Anxiety Stress Scale-21 ${ }^{31}$ (DASS-21). DASS-21 is a short version of the 42 -item DASS. It is a dimensional self-report scale designed to measure negative emotional states of depression, anxiety, and stress. The scale has 21 items for these three scales with 7 items each. Responses are rated on a 4-point scale that measures how much each item applies to the respondent over the past week. The DASS-21 has demonstrated good psychometric properties ${ }^{32}$ : however, when administered in children and adolescents, only one (general) component is extracted ${ }^{33}$.

Bipolar Spectrum Diagnostic Scale ${ }^{34}$ (BSDS). BSDS is a narrative-based scale which assesses the entire bipolar spectrum, gathering hypomania or subthreshold manic states. The BSDS has been demonstrated to be an efficient self-rating scale with excellent sensitivity, making it useful in detecting subthreshold states of bipolar illness ${ }^{34,35}$.

Personality Inventory for DSM-5, Brief version ${ }^{36,37}$ (PID-5-BF). PID-5-BF assesses the recent maladaptive personality trait model proposed in DSM-5 (Alternative Model of Personality Disorder, AMPD). This 25-item version is intended as a screening instrument for personality pathology in adults and adolescents. The PID-5-BF measures five maladaptive traits (Negative Affectivity, Detachment, Antagonism, Disinhibition, and Psychoticism) using 5 items for each trait. Two recent studies on the psychometric properties of the PID-5-BF suggest that the PID-5-BF is a reliable screening tool of DSM-5 AMPD maladaptive traits $^{38,39}$.

This article is protected by copyright. All rights reserved. 
Towards a pluripotent at-risk mental state

Davos Assessment of Cognitive Biases Scale ${ }^{40}$ (DACOBS). DACOBS aims to measure four cognitive biases specific to positive symptoms of psychosis (jumping to conclusions, belief inflexibility, selective attention for threat, external attribution bias), two cognitive limitations (social cognition problems, subjective cognitive problems) and avoidance behaviour. It has a total of 42 items scored on a 7-point Likert scale with a two-week time frame. The DACOBS has demonstrated excellent reliability (Cronbach's alpha $=.90)^{40}$, good internal consistency, and convergent validity ${ }^{41}$.

Munich Chronotype Questionnaire (MCTQ) $)^{42}$. MCTQ quantitatively assesses 'chronotype', which refers to individual differences in the timing of sleep within the 24-hour day. The MCTQ assesses information on sleep and activity separately for work and work-free days, thereby obtaining chronotype based on the midpoint between sleep onset/offset on free days corrected for oversleep (as a result of sleep debt accumulated during work days) ${ }^{43}$.

Insomnia Severity Index ${ }^{44}$ (ISI). The ISI assesses the severity of both nighttime and daytime symptoms of insomnia. It has a total of 7 items rated on a 4-point Likert scale that assess sleep-onset and sleep maintenance difficulties, satisfaction with sleep pattern, interference with daily functioning, impairment attributed to the sleep problem and degree of distress caused by these difficulties. The ISI has been demonstrated to be a reliable and valid instrument to assess insomnia in the adult ${ }^{44,45}$ as well as adolescent population ${ }^{46}$.

\section{Statistical Analyses}

\section{Power}

There are two primary aims of this study. One is to compare the transition rates of the CHARMS+ (expected transition rate 20\%) and CHARMS- (expected transition rate 3\%) groups. Allowing for a $20 \%$ drop-out rate (based on previous UHR research), at 5\% significance level we would require 76 CHARMS+ and 152 CHARMS- individuals in order to have $80 \%$ power. A larger sample size is required for CHARMS- because the expected transition rate for this group is very low $(3 \%)$ requiring a larger sample for a greater number of transitions in order to achieve adequate power. The other aim is to

This article is protected by copyright. All rights reserved. 
Towards a pluripotent at-risk mental state

estimate the transition rate of the CHARMS+ group. We plan to recruit 160 individuals for this group which would give us a reasonable precision of $\pm 7 \%$ for the estimation with a $95 \%$ confidence level. Deriving a sample to address the two aims together and rounding up the numbers, requires a total sample size of 320 (160 for each group).

\section{Data analysis}

The Kaplan-Meier method will be used to estimate the rate of transition to Stage 2 disorder for the CHARMS+ and CHARMS- groups. Cox regression will be used to test for the difference in hazard rate between the two groups and also to explore potential predictors of progression to Stage 2 disorders. Overlap in the outcomes of interest (e.g., a participant who transitions to full-threshold psychosis and also to severe major depression) will not present a problem statistically or conceptually, as we are concerned with transition to and prediction of any Stage 2 'exit syndrome', rather than specific exit syndromes. Multilevel regression will be used to compare the groups on continuous outcomes at 6 and 12 months and to investigate the association between baseline risk factors and 6 and 12 month symptomatic/functional outcome in CHARMS+.

\section{Discussion}

This paper presents the study methodology of the CHARMS study, the first empirical investigation of a novel transdiagnostic set of clinical criteria for prospectively identifying young people at-risk of developing a range of serious mental illnesses. By building on previous UHR criteria and focusing on transdiagnostic characteristics of mental illness, increasing incidence rate and statistical power, this study may introduce a new, more powerful paradigm for patient identification and investigation of the mechanisms of disorder onset.

Testing and validating this broader set of at risk-criteria recognises the heterogeneity of pathways and outcomes for young people with sub-syndromal psychopathology and opens the door to trialling preventive interventions in this group (e.g., psychosocial interventions, acetylcysteine, neuroprotective agents such as omega- 3 fatty acids) that are proportionate to presenting problems and which may be effective in delaying or preventing a range of serious mental illnesses. 
Towards a pluripotent at-risk mental state

This article is protected by copyright. All rights reserved. 


\section{References}

1. Fusar-Poli $P$, Borgwardt $S$, Bechdolf $A$, et al. The psychosis high-risk state: a comprehensive state-of-the-art review. JAMA Psychiatry. 2013; 70: 107-20.

2. $\quad$ Fusar-Poli P, Bonoldi I, Yung AR, et al. Predicting psychosis: meta-analysis of transition outcomes in individuals at high clinical risk. Arch Gen Psychiatry. 2012; 69: 220-9.

3. Hartmann JA, Yuen HP, McGorry PD, et al. Declining transition rates to psychotic disorder in "ultra-high risk" clients: Investigation of a dilution effect. Schizophr Res. 2016; 170: 130-6.

4. Yung AR, Yuen HP, Berger $G$, et al. Declining transition rate in ultra high risk (prodromal) services: dilution or reduction of risk? Schizophr Bull. 2007; 33: 673-81.

5. Fusar-Poli P, Nelson B, Valmaggia L, Yung AR, McGuire PK. Comorbid depressive and anxiety disorders in 509 individuals with an at-risk mental state: impact on psychopathology and transition to psychosis. Schizophr Bull. 2014; 40: 120-31.

6. Lin A, Wood SJ, Nelson B, Beavan A, McGorry P, Yung AR. Outcomes of nontransitioned cases in a sample at ultra-high risk for psychosis. Am J Psychiatry. 2015; 172: 249-58.

7. Rutigliano G, Valmaggia L, Landi $P$, et al. Persistence or recurrence of non-psychotic comorbid mental disorders associated with 6-year poor functional outcomes in patients at ultra high risk for psychosis. J Affect Disord. 2016; 203: 101-10.

8. Cuijpers P. Examining the effects of prevention programs on the incidence of new cases of mental disorders: the lack of statistical power. Am J Psychiatry. 2003; 160: 1385-91.

9. Cuijpers P, Van Straten A, Smit F. Preventing the incidence of new cases of mental disorders: a meta-analytic review. J Nerv Ment Dis. 2005; 193: 119-25.

10. McGorry PD, Nelson B, Markulev C, et al. Effect of omega-3 Polyunsaturated Fatty Acids in Young People at Ultrahigh Risk for Psychotic Disorders: The NEURAPRO Randomized Clinical Trial. JAMA Psychiatry. 2017; 74: 19-27.

11. Morrison AP, French P, Stewart SL, et al. Early detection and intervention evaluation for people at risk of psychosis: multisite randomised controlled trial. BMJ. 2012; 344: e2233.

12. McGorry P. Early clinical phenotypes and risk for serious mental disorders in young people: need for care precedes traditional diagnoses in mood and psychotic disorders. Can J Psychiatry. 2013; 58: 19-21.

13. McGorry PD. Beyond psychosis risk: early clinical phenotypes in mental disorder and the subthreshold pathway to safe, timely and effective care. Psychopathology. 2014; 47: 285-6.

14. Hickie IB, Scott EM, Hermens DF, et al. Applying clinical staging to young people who present for mental health care. Early Interv Psychiatry. 2013; 7: 31-43.

15. McGorry PD. Issues for DSM-V: clinical staging: a heuristic pathway to valid nosology and safer, more effective treatment in psychiatry. Am J Psychiatry. 2007; 164: 859-60.

16. McGorry PD, Hickie IB, Yung AR, Pantelis C, Jackson HJ. Clinical staging of psychiatric disorders: a heuristic framework for choosing earlier, safer and more effective interventions. Aust $\mathrm{N}$ Z J Psychiatry. 2006; 40: 616-22.

17. McGorry PD, McFarlane C, Patton GC, et al. The prevalence of prodromal features of schizophrenia in adolescence: a preliminary survey. Acta Psychiatr Scand. 1995; 92: 241-9.

18. Gore FM, Bloem PJ, Patton GC, et al. Global burden of disease in young people aged 10-24 years: a systematic analysis. Lancet. 2011; 377: 2093-102.

19. Chanen AM, McCutcheon L. Prevention and early intervention for borderline personality disorder: current status and recent evidence. Br J Psychiatry Suppl. 2013; 54: s24-9. 
20. Yung AR, Yuen HP, McGorry PD, et al. Mapping the onset of psychosis: the Comprehensive Assessment of At-Risk Mental States. Aust N Z J Psychiatry. 2005; 39: 964-71.

21. First MB, Williams JBW, Karg RS, RL S. Structured Clinical Interview for DSM-5-Research Version (SCID-5 for DSM-5, Research Version; SCID-5-RV). Arlington, VA: American Psychiatric Association; 2015.

22. First MB, Williams JBW, Benjamin LS, RL S. Structured Clinical Interview for DSM-5 Personality Disorders. Washington, D.C.: American Psychiatric Association; 2016.

23. American Psychiatric Association. Diagnostic and Statistical Manual of Mental Disorders, Fifth Edition. Arlington VA: American Psychiatric Association; 2015.

24. First M, Gibbon M, Spitzer RL, Williams J, LS B. Structured Clinical Interview for DSM-IV Axis II Personality Disorders, (SCID-II), Personality Questionnaire. Washington, D.C.: American Psychiatric Press, Inc.; 1997.

25. Rush AJ, Trivedi $\mathrm{MH}$, Ibrahim HM, et al. The 16-Item Quick Inventory of Depressive Symptomatology (QIDS), clinician rating (QIDS-C), and self-report (QIDS-SR): a psychometric evaluation in patients with chronic major depression. Biol Psychiatry. 2003; 54: 573-83.

26. Goldman HH, Skodol AE, Lave TR. Revising axis V for DSM-IV: a review of measures of social functioning. Am J Psychiatry. 1992; 149: 1148-56.

27. Auther A, Smith C, Cornblatt B. Global Functioning: Social Scale (GF: Social). Glen Oaks: Zucker-Hillside Hospital; 2006.

28. Niendam TA, Bearden CE, Johnson JK, TD C. Global Functioning: Role Scale (GF: Role). Los Angeles, CA: University of California, Los Angeles; 2006.

29. Young RC, Biggs JT, Ziegler VE, Meyer DA. A rating scale for mania: reliability, validity and sensitivity. Br J Psychiatry. 1978; 133: 429-35.

30. Lam RW, Michalaak EE, Swinson RP. Assessment scales in depression, mania and anxiety. London, UK: Taylor \& Francis; 2004.

31. Lovibond SH, Lovibond PF. Manual for the Depression Anxiety Stress Scales. 2nd ed. Sydney: Psychology Foundation; 1995.

32. Weiss RB, Aderka IM, Lee J, Beard C, Bjorgvinsson T. A Comparison of Three Brief Depression Measures in an Acute Psychiatric Population: CES-D-10, QIDS-SR, and DASS-21-DEP. Journal of Psychopathology and Behavioral Assessment. 2015; 37: 217-30.

33. Patrick J, Dyck M, Bramston P. Depression Anxiety Stress Scale: is it valid for children and adolescents? J Clin Psychol. 2010; 66: 996-1007.

34. Nassir Ghaemi S, Miller CJ, Berv DA, Klugman J, Rosenquist KJ, Pies RW. Sensitivity and specificity of a new bipolar spectrum diagnostic scale. J Affect Disord. 2005; 84: 273-7.

35. Baldassano CF. Assessment tools for screening and monitoring bipolar disorder. Bipolar Disord. 2005; 7 Suppl 1: 8-15.

36. Krueger RF, Derringer J, Markon KE, Watson D, Skodol AE. Initial construction of a maladaptive personality trait model and inventory for DSM-5. Psychol Med. 2012; 42: 1879-90.

37. Online assessment measures: The Personality Inventory for DSM-5-Brief Form (PID-5-BF) [database on the Internet]. 2013 [cited.

38. Fossati A, Somma A, Borroni S, Maffei C, Markon KE, Krueger RF. A Head-to-Head Comparison of the Personality Inventory for DSM-5 (PID-5) With the Personality Diagnostic Questionnaire-4 (PDQ-4) in Predicting the General Level of Personality Pathology Among Community Dwelling Subjects. J Pers Disord. 2015: 1-13. 
39. Anderson JL, Sellbom M, Salekin RT. Utility of the Personality Inventory for DSM-5-Brief Form (PID-5-BF) in the Measurement of Maladaptive Personality and Psychopathology. Assessment. 2016.

40. van der Gaag M, Schutz C, Ten Napel A, et al. Development of the Davos assessment of cognitive biases scale (DACOBS). Schizophr Res. 2013; 144: 63-71.

41. Bastiaens T, Claes L, Smits D, De Wachter D, van der Gaag M, De Hert M. The Cognitive Biases Questionnaire for Psychosis (CBQ-P) and the Davos Assessment of Cognitive Biases (DACOBS): validation in a Flemish sample of psychotic patients and healthy controls. Schizophr Res. 2013; 147: 310-4.

42. Roenneberg T, Wirz-Justice A, Merrow M. Life between clocks: Daily temporal patterns of human chronotypes. Journal of Biological Rhythms. 2003; 18: 80-90.

43. Roenneberg T, Keller LK, Fischer D, Matera JL, Vetter C, Winnebeck EC. Human activity and rest in situ. Methods Enzymol. 2015; 552: 257-83.

44. Bastien $\mathrm{CH}$, Vallieres $\mathrm{A}$, Morin $\mathrm{CM}$. Validation of the Insomnia Severity Index as an outcome measure for insomnia research. Sleep Medicine. 2001; 2: 297-307.

45. Morin CM, Belleville G, Belanger L, Ivers H. The Insomnia Severity Index: psychometric indicators to detect insomnia cases and evaluate treatment response. Sleep. 2011; 34: 601-8.

46. Chung KF, Kan KK, Yeung WF. Assessing insomnia in adolescents: comparison of Insomnia Severity Index, Athens Insomnia Scale and Sleep Quality Index. Sleep Med. 2011; 12: 463-70. 
Table 1 CHARMS criteria

\begin{tabular}{|l|l|l|}
\hline Subgroup & Instrument & Description \\
\hline $\begin{array}{l}\text { Psychosis trait } \\
\text { vulnerability } \\
\text { group }\end{array}$ & $\begin{array}{l}\text { FHI, SCID-5- } \\
\text { PD, SOFAS }\end{array}$ & $\begin{array}{l}\text { Family history of psychosis in first degree relative OR Schizotypal Personality Disorder } \\
\text { AND } \\
\text { SOFAS score of } 50 \text { or less for over 12 months OR SOFAS score at least 30\% below previous level }\end{array}$ \\
\hline $\begin{array}{l}\text { Bipolar trait } \\
\text { vulnerability } \\
\text { group }\end{array}$ & FHI, SCID-5 & $\begin{array}{l}\text { Depression + Cyclothymic features / Genetic Risk Group: } \\
\text { Depression: For at least 1 week: depressed mood, or loss of interest or pleasure and at least 2 criteria from the list: (1) } \\
\text { significant weight loss, (2) insomnia or hypersomnia nearly every day, (3) psychomotor retardation or agitation, (4) } \\
\text { fatigue or loss of energy, (5) feelings of worthlessness or excessive or inappropriate guilt, (6) diminished ability to think } \\
\text { or concentrate, (7) recurrent thoughts of death, recurrent suicidal ideation. The episode (a) cannot be due to the direct } \\
\text { physiological effects of a substance or condition (b) doesn't need to cause a clinically significant drop in functioning. } \\
\text { AND }\end{array}$ \\
$\begin{array}{l}\text { Cyclothymic features: For a minimum of 6 months (lifetime) high and low mood (no more than 2 consecutive months } \\
\text { without symptoms) and at least 3 criteria from the list: (1) decreased need for sleep (e.g. feels rested after only three } \\
\text { hours sleep), (2) increased energy, (3) inflated self-esteem or grandiosity, (4) increased goal directed activity, (5) } \\
\text { restlessness, (6) more talkative than usual or pressure to keep talking, (7) unusual ideas, clear thinking (8) troublesome } \\
\text { behaviour (9) inappropriate sense of humour. The episode (a) cannot be due to the direct physiological effects of a } \\
\text { substance or condition and (b) doesn't need to cause a clinically significant drop in functioning. } \\
\text { OR }\end{array}$ \\
$\begin{array}{l}\text { Genetic risk: First degree relative with bipolar disorder. } \\
\end{array}$
\end{tabular}

This article is protected by copyright. All rights reserved. 


\begin{tabular}{|c|c|c|}
\hline $\begin{array}{l}\text { Attenuated } \\
\text { psychotic } \\
\text { symptoms } \\
\text { group }\end{array}$ & CAARMS & $\begin{array}{l}\text { Intensity: Global Rating Scale Score of 3-5 on Unusual Thought Content subscale, 3-5 on Non-Bizarre Ideas subscale, 3-4 } \\
\text { on Perceptual Abnormalities subscale and/or 4-5 on Disorganised Speech subscales (symptoms present for at least one } \\
\text { week in the last year) AND Frequency: Scale Score of 3-6 on Unusual Thought Content, Non-Bizarre Ideas, Perceptual } \\
\text { Abnormalities and/or Disorganised Speech subscales } \\
\text { Intensity: Global Rating Scale Score of } 6 \text { on Unusual Thought Content subscale, } 6 \text { on Non-Bizarre Ideas subscale, 5-6 on } \\
\text { Perceptual Abnormalities subscale and/or } 6 \text { on Disorganised Speech subscales (symptoms present for at least one week } \\
\text { in the last year) AND Frequency: Scale Score of } 3 \text { on Unusual Thought Content, Non-Bizarre Ideas, Perceptual } \\
\text { Abnormalities and/or Disorganised Speech subscales }\end{array}$ \\
\hline $\begin{array}{l}\text { Attenuated } \\
\text { (hypo)manic } \\
\text { symptom group }\end{array}$ & SCID-5 & 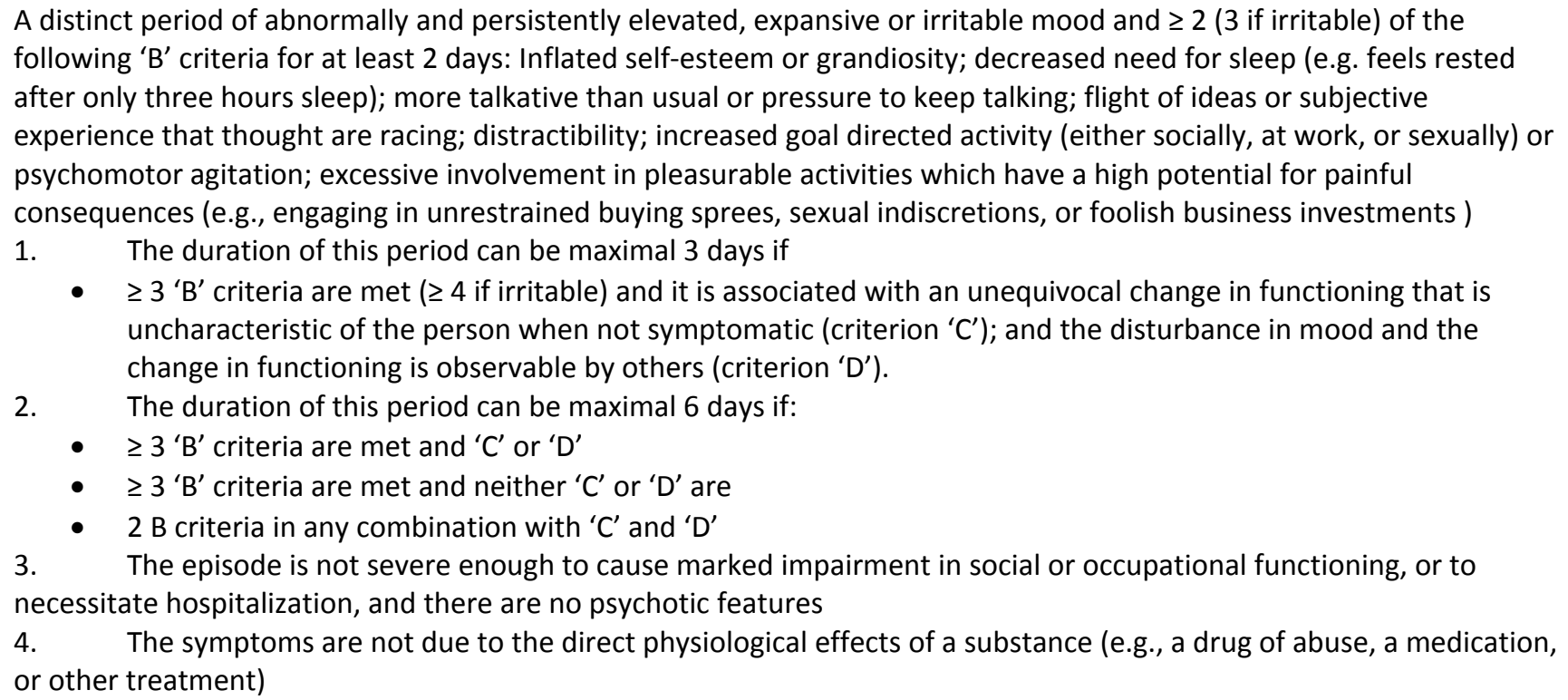 \\
\hline
\end{tabular}




\begin{tabular}{|c|c|c|c|}
\hline $\begin{array}{l}\text { Moderate } \\
\text { (Attenuated) } \\
\text { depression } \\
\text { group }\end{array}$ & $\begin{array}{l}\text { SCID-5, } \\
\text { QIDS-C }\end{array}$ & $\begin{array}{l}\text { Major Depressive Episode (current or past) } \\
\text { For at least } 2 \text { weeks: depressed mood, or loss of interest or pleasure }+ \text { at least } 5 \text { criteria from the list: (1) significant } \\
\text { weight loss, ( } 2 \text { ) insomnia or hypersomnia nearly every day, (3) psychomotor retardation or agitation, (4) fatigue or loss } \\
\text { of energy, (5) feelings of worthlessness or excessive or inappropriate guilt, (6) diminished ability to think or concentrate, } \\
\text { (7) recurrent thoughts of death, recurrent suicidal ideation. The MDE must also: (a) not be due to the direct } \\
\text { physiological effects of a substance, (b) cause a clinically significant drop in functioning and (c) not be better accounted } \\
\text { for by bereavement. } \\
\text { Current QIDS Score: } 11-15\end{array}$ & $\begin{array}{l}\mathrm{FHI}= \\
\text { Family }\end{array}$ \\
\hline $\begin{array}{l}\text { Attenuated } \\
\text { borderline } \\
\text { personality } \\
\text { group }\end{array}$ & SCID-5-PD & $\begin{array}{l}\text { For at least } 6 \text { months: at least } 2 \text { but less than } 5 \text { criteria from the list: (1) frantic efforts to avoid real or imagined } \\
\text { abandonment (2) a pattern of unstable and intense interpersonal relationships characterised by alternating between } \\
\text { extremes of idealization and devaluation (3) identity disturbance: markedly and persistently unstable self-image or } \\
\text { sense of self (4) impulsivity in at least two areas that are potentially self-damaging (e.g. spending, sex, substance abuse, } \\
\text { reckless driving, binge eating). This does not include suicidal or self-harming behaviour (5) recurrent suicidal behaviour, } \\
\text { gestures, or threats, or self-mutilating behaviour (6) affective instability due to a marked reactivity of mood - intense } \\
\text { feelings that can last from a few hours to a few days (7) chronic feelings of emptiness (8) inappropriate intense anger or } \\
\text { difficulty controlling anger (9) transient, stress-related paranoid ideas or severe dissociative symptoms. }\end{array}$ & $\begin{array}{l}\text { History } \\
\text { Index } \\
\text { [Orygen]; } \\
\text { SCID-5= } \\
\text { Structured } \\
\text { Clinical } \\
\text { Interview } \\
\text { for DSM-5; }\end{array}$ \\
\hline $\begin{array}{l}\text { Brief limited } \\
\text { intermittent } \\
\text { psychotic } \\
\text { symptom } \\
\text { (BLIPS) group* }\end{array}$ & CAARMS & $\begin{array}{l}\text { Intensity: Global Rating Scale Score of } 6 \text { on Unusual Thought Content subscale, } 6 \text { on Non-Bizarre Ideas subscale, } 5 \text { or } 6 \\
\text { on Perceptual Abnormalities subscale and/or } 6 \text { on Disorganised Speech subscales (symptoms present for less than one } \\
\text { week in the last year) AND Frequency: Frequency Scale Score of 4-6 on Unusual Thought Content, Non-Bizarre Ideas, } \\
\text { Perceptual Abnormalities and/or Disorganised Speech subscales }\end{array}$ & $\begin{array}{l}\text { SOFAS=So } \\
\text { cial and } \\
\text { Occupatio } \\
\text { nal } \\
\text { Functionin } \\
\text { g Scale; } \\
\text { CAARMS= }\end{array}$ \\
\hline
\end{tabular}

The Comprehensive Assessment of At-Risk Mental States; QIDS - C= Quick Inventory of Depressive Symptomatology - Clinician rated; SCID-5-PD= Structured Clinical Interview for DSM-5 Personality Disorders

This article is protected by copyright. All rights reserved. 
Table 2. Schedule of Assessments

\begin{tabular}{|c|c|c|c|c|}
\hline & VISIT NUMBER & 1 & 2 & 3 \\
\hline & Assessment & Baseline & Month $6( \pm 2 w)$ & Month $12( \pm 2 w)$ \\
\hline \multirow{4}{*}{ 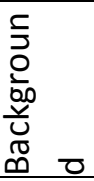 } & Informed Consent & $\mathrm{X}$ & & \\
\hline & Demographics, medical \& & $x$ & & \\
\hline & Present/past treatment & $\mathrm{X}$ & $\mathrm{X}$ & $\mathrm{X}$ \\
\hline & $\mathrm{FHI}$ & $\mathrm{X}$ & & \\
\hline \multirow{7}{*}{ 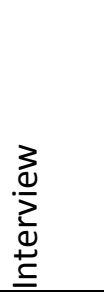 } & CAARMS & $x$ & $\mathrm{X}$ & $x$ \\
\hline & SCID-5 & $X$ & $\mathrm{X}$ & $\mathrm{X}$ \\
\hline & SCID-5-PD* & & & \\
\hline & QIDS-C & $x$ & $\mathrm{X}$ & $\mathrm{X}$ \\
\hline & SOFAS & $x$ & $\mathrm{X}$ & $x$ \\
\hline & GFS/GFR & $\mathrm{X}$ & $\mathrm{X}$ & $\mathrm{X}$ \\
\hline & YMRS & $x$ & $x$ & $\mathrm{X}$ \\
\hline \multirow{5}{*}{$\begin{array}{l}\frac{t}{0} \\
\frac{0}{0} \\
\frac{1}{1} \\
\frac{1}{d} \\
\stackrel{\sim}{N}\end{array}$} & DASS-21 & $\mathrm{X}$ & $\mathrm{X}$ & $\mathrm{X}$ \\
\hline & DACOBS & $x$ & & \\
\hline & PID-5-BF & $x$ & $\mathrm{X}$ & $\mathrm{X}$ \\
\hline & BSDS & $\mathrm{X}$ & & \\
\hline & Sleep Questionnaire & $x$ & $\mathrm{X}$ & $x$ \\
\hline
\end{tabular}

FHI = Family History Index [Orygen]; CAARMS= The Comprehensive Assessment of At-Risk Mental States; SCID-5= Structured Clinical Interview for DSM-5; SCID-5-PD= Structured Clinical Interview for DSM-5 Personality Disorders; *Borderline personality disorder module and schizotypal personality disorder module; QIDS - C= Quick Inventory of Depressive Symptomatology - Clinician rated; SOFAS=Social and Occupational Functioning Scale; GFS= Global Functioning Scale: Social and GFR= Global Functioning Scale: Role; YMRS= Young Mania Rating Scale; DASS-21 = Depression Anxiety Stress Scale (21 items version); DACOBS= Davos Assessment of Cognitive Biases Scale; PID-5-BF= The Personality Inventory for DSM-5, Brief Version; BSDS= Bipolar Spectrum Diagnostic Scale; Sleep Questionnaire= Insomnia Severity Index and Munich ChronoType Questionnaire.

This article is protected by copyright. All rights reserved. 
Towards a pluripotent at-risk mental state

Figure Legends

Figure 1. Illustration of the clinical staging model for mental disorders.

This article is protected by copyright. All rights reserved. 


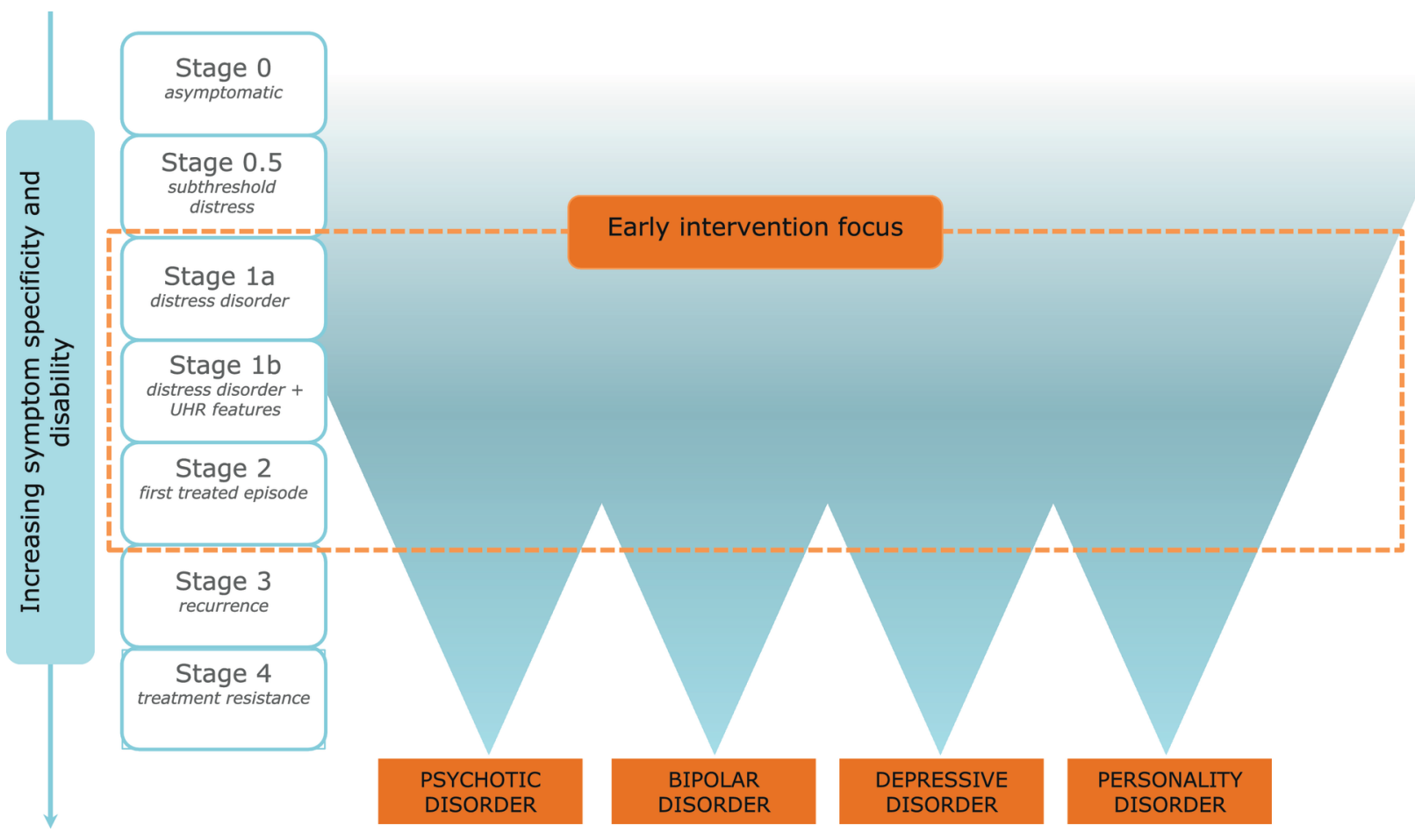

figure 1[4]_converted.eps 


\section{University Library}

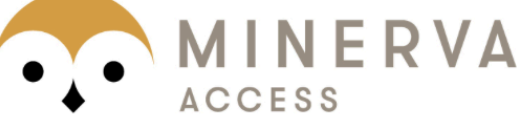

A gateway to Melbourne's research publications

Minerva Access is the Institutional Repository of The University of Melbourne

\section{Author/s:}

Hartmann, JA;Nelson, B;Spooner, R;Amminger, GP;Chanen, A;Davey, CG;McHugh, M;Ratheesh, A;Treen, D;Yuen, HP;McGorry, PD

Title:

Broad clinical high-risk mental state (CHARMS): Methodology of a cohort study validating criteria for pluripotent risk

Date:

2019-06-01

Citation:

Hartmann, J. A., Nelson, B., Spooner, R., Amminger, G. P., Chanen, A., Davey, C. G., McHugh, M., Ratheesh, A., Treen, D., Yuen, H. P. \& McGorry, P. D. (2019). Broad clinical high-risk mental state (CHARMS): Methodology of a cohort study validating criteria for pluripotent risk. EARLY INTERVENTION IN PSYCHIATRY, 13 (3), pp.379-386. https:// doi.org/10.1111/eip.12483.

Persistent Link:

http://hdl.handle.net/11343/293552 